\title{
A METAMORFOSE DO CONCEITO DE REGIÃO: LEITURAS DE MILTON SANTOS ${ }^{1}$
}

\author{
Thiago Macedo Alves de Brito ${ }^{2}$ \\ Mestre em Geografia, IGC-UFMG
}

\section{Introdução}

O desenvolvimento das ciências da natureza, principalmente a partir do século XIX, influenciou fortemente a metodologia das ciências humanas. Para Milton Santos (2003), a região apareceu na geografia moderna, em meados do século XIX, calcada pelas disciplinas da natureza. Foi a partir da geologia que a geografia científica incorporou, em seu vocabulário, o termo região. Ela apareceu, nesse contexto, como um conjunto de bacias hidrográficas orientadas pelo relevo.

É na França de Vidal de la Blache que a categoria região ganhará maior destaque no meio acadêmico geográfico. A geografia francesa põe no centro do debate o conceito de gênero de vida, que, na sociologia e na antropologia, surgiu como modo de vida ou morfologia social. O conceito de gênero de vida se refere a uma relação específica entre homem e natureza num determinado lugar, onde cultura, política, economia e sociedade se formam a partir de suas necessidades internas, conforme uma dinâmica que é própria da região. Essa geografia do gênero de vida significava que o entorno natural oferecia possibilidades para as culturas, que, à sua maneira, se apropriavam dele para seu próprio benefício (SANTOS, 2003).

O conceito de gênero de vida da escola francesa está articulado ao conceito de paisagem. A ideia de que no decorrer da história dos modos de produção se constroem objetos - que guardam consigo todo significado referente ao ato de sua elaboração - mostra que esses são marcados pela produção cultural de uma determinada extensão territorial e de uma determinada época. A imagem desses objetos, produzidos em conjunto com os objetos naturais, configura a paisagem, nesse contexto, considerada como sinônimo de região, uma imagem coesa e harmônica. A essa

\footnotetext{
${ }^{1}$ Este texto é derivado do capítulo 3 da dissertação de mestrado de título Região: leituras possíveis de Milton Santos, defendida em junho de 2007 no Departamento de Geografia do IGC-UFMG.
}

${ }^{2}$ Endereço eletrônico do autor: tmadebrito@gmail.com 
associação, entre região e paisagem, deve-se o equívoco de tornar a forma, a paisagem, como a realidade. Sua formação histórica deveria ser examinada para que a realidade não se dissolvesse na aparência da paisagem. Mas, na geografia, as noções de região e paisagem estão intimamente relacionadas. Esse vínculo é tão forte que na Alemanha, segundo Sorre (1967), elas se expressam pela mesma palavra: Landschaft.

\section{A região segundo Milton Santos}

O desenvolvimento da história, segundo Milton Santos (2003), foi lento, por muito tempo permitindo que a região fosse vista como espaço de identidade. Essa identidade regional, que se modificava a passos vagarosos, trazia o enorme peso do passado, das tradições. Os objetos que representavam uma região, que nela se consolidavam, forneciam a impressão de algo praticamente contido em si. As regiões, que se formavam a partir da solidariedade orgânica entre os povos e seus territórios, produziam identidades consistentes ao longo do tempo e limites espaciais coesos entre elas. A solidariedade era fruto de uma organização local, econômica, social, política e cultural que satisfazia as necessidades de cada região. A diferença entre as regiões se dava pelas peculiaridades das relações internas entre os homens e a natureza, sem a presença, necessariamente, de mediação externa.

Nos países centrais, as regiões pareciam ter certa autonomia em virtude da fluidez do espaço e em razão de as atratividades do centro urbano terem facilitado o acesso aos serviços. Nos países subdesenvolvidos, onde a industrialização é tardia, a criação de metrópoles nacionais é, também, retardatária devido à falta de integração nacional. Eram as metrópoles regionais que exerciam o papel de fornecedoras de bens e serviços. À falta de integração nacional, essas metrópoles estabeleciam maiores laços políticos e econômicos com centros do sistema mundial (SANTOS, 1985).

Nas regiões subdesenvolvidas, os espaços eram, sobretudo, históricos, onde o peso do passado influenciava bastante a configuração da paisagem. As relações econômicas e culturais se mantinham internamente estáveis, fato que levou especialistas a afirmar a coerência interna das regiões, deixando encobertas as relações externas que influenciavam a conformação regional. "A falta, porém, de reconhecimento dessas relações mais amplas assegurava a permanência de uma noção que, desde a segunda revolução industrial e a implantação do imperialismo, já não mais correspondia à realidade" (SANTOS, 1985:66). 
$\mathrm{Na}$ verdade, as regiões dos países subdesenvolvidos eram transformadas e organizadas de acordo com interesses externos. Esses interesses, porém, nem sempre atingiam as regiões da mesma maneira, pois dependiam das especificidades locais que eram importantes para a reprodução do capital. As forças de modernização, vindas do exterior, eram seletivas em suas formas e ações, não atingiam todo o espaço num mesmo período de tempo, formando uma história espacial seletiva (SANTOS, 1979).

A cada nova função do espaço regional, no contexto internacional, novas forças externas de modernização entravam em contato com uma ou mais regiões e as modificavam de acordo com suas necessidades e características regionais. Essa convergência ou, muitas vezes, divergência entre as forças externas e internas na região criava certa instabilidade no espaço, causando desequilíbrios e desigualdades sociais.

A formação das regiões nos países subdesenvolvidos está conectada com os espaços dos países desenvolvidos, pois é a partir de suas modernizações e, consequentemente, de sua expansão que se entende essa fragmentação do mundo em regiões funcionais. $O$ impacto da modernização nos espaços derivados é de fundamental importância para a compreensão da região. Esses espaços derivados, como afirma Milton Santos, dependem de determinações externas e, também, de suas histórias internas.

Todo espaço conhece assim uma evolução própria, resultado de uma conjunção de forças externas pertencentes a um sistema cujo centro encontra-se nos países-polos e de forças internas já existentes nesse espaço. Resulta daí a diversidade das condições de subdesenvolvimento e a originalidade das situações para cada lugar (SANTOS, 1979:25).

A internacionalização do capital, em seu novo período técnicocientífico, mostrou a debilidade do antigo conceito de região. A aceleração da acumulação de capital tornou mais seletivas suas ações no espaço. O edifício regional estável e coeso dá lugar à instabilidade e às frequentes mudanças em sua forma e seu conteúdo. As relações internas estão mais condicionadas pelas demandas externas, o que não elimina a região, mas gera mudanças em seu conteúdo. "Mas o que faz a região não é a longevidade do edifício, mas a coerência funcional, que a distingue das outras entidades, vizinhas ou não. $\mathrm{O}$ fato de ter vida curta não muda a definição do recorte territorial" (SANTOS, 1997:197). 
Vale lembrar que os vetores externos, em contato com cada região, são muito maiores hoje, no período técnico-científico-informacional, do que em fases anteriores do capitalismo, o que torna a região um espaço muito mais complexo e dinâmico. O tempo acelerado do mundo modifica os eventos locais, aumenta as disparidades regionais, mas o fenômeno regional ganha universalidade. É só a partir da universalidade, na opinião de Milton Santos (1999), que se compreendem as realidades regionais, porque é de fora que vêm seus impulsos e seus deveres.

Graças ao domínio da fluidez e da velocidade de circulação das mercadorias e das informações - características do mundo globalizado -, alguns declamaram o fim das especificidades regionais, irrelevantes diante da homogeneidade imposta globalmente. No entanto, Milton Santos relembra que, ao contrário do que parece, a região se torna ainda mais importante no mundo contemporâneo, tendo em vista,

em primeiro lugar, o tempo acelerado, acentuando a
diferenciação dos eventos, aumentando a diferenciação dos
lugares; em segundo lugar, já que o espaço se torna mundial,
o ecúmeno se redefine, com a extensão de todo ele do
fenômeno de região. As regiões são o suporte e a condição de
relações globais que de outra forma não se realizam. Agora,
exatamente, é que não se pode deixar de considerar a região,
ainda que reconheçamos como um espaço de conveniência
mesmo que a chamemos por outro nome (SANTOS,
1997:196).

$\mathrm{Na}$ realidade, o que se passa é o contrário da homogeneização. A velocidade dos fluxos e a instantaneidade dos eventos reforçam a conformação da região, fazem com que os espaços se tornem especializados, normatizados a partir das necessidades globais da produção, da circulação, da distribuição e do consumo.

As regiões deixam de ser sede de seu próprio poder, de sua própria gestão. Fruto de uma solidariedade orgânica, elas passam a se constituir por meio de uma solidariedade organizacional. No antigo conceito de região, a base era a solidariedade orgânica entre seus habitantes, que estabeleciam uma relação longeva com seu lugar e se organizavam segundo as necessidades da própria região. Atualmente, ela é definida pela solidariedade que se constitui dentro dela, mas a partir de uma organização que vem de fora. A solidariedade, então, deixa de ser orgânica - originária da própria vida da região e das variáveis constitutivas dela - e se transforma em solidariedade organizacional (SANTOS, 2003). 
Max Sorre (1967) foi o primeiro, de acordo com Milton Santos, a falar da nova conformação da região. Ele denominou as regiões dos países subdesenvolvidos de paisagens derivadas. Elas são, sobretudo, resultado da emigração dos países desenvolvidos para os subdesenvolvidos. Os migrantes, que rompem seus laços políticos com as metrópoles, continuam conservando os traços físicos e humanos do lugar de onde vieram. Eles trazem consigo suas culturas, seus gêneros de vida e reproduzem suas paisagens.

Com Milton Santos, as paisagens passam a ser, também, derivadas de fluxos econômicos, de vontades políticas, de informação, de normas, de hierarquias que transformam por completo a paisagem regional. Indo além da contribuição de Sorre, Milton Santos incorpora o conceito de região funcional (SANTOS, 1985, 1991), já presente nas obras de Hartshorne e de Bernard Kaiser.

Segundo Kaiser (1973), reconhecer os limites regionais não é mais tarefa dos geógrafos, não é mais seu objeto principal de pesquisa. $\mathrm{Na}$ contemporaneidade, tende-se a considerar a região muito mais um campo de ações concomitantes de complexas e intensas variáveis do que uma inscrição espacial precisa, equilibrada e de caráter homogêneo.

Os elementos essenciais da realidade regional apontados por Kaiser (1973) são: o caráter concreto e a realidade histórica da região que enquadra a dimensão física como ponto inicial da realidade regional; o equilíbrio de forças em que pesa a importância do passado; as relações e características comuns de seus habitantes, como sua organização econômica e social; sua organização a partir de um centro urbano. Por fím, ele afirma que a região autossustentada não existe mais; ela é funcional em relação ao exterior e dele depende para sua própria dinâmica.

Espaço limitado, a região participa de um espaço mais amplo; nesse sentido, ela é dominada - e essa dependência desempenha em sua evolução um papel muitas vezes preponderante - porque ela é ao mesmo tempo aberta e integrada. O poder, financeiro e político, isto é, a capacidade superior de decisão, escapa sempre à região; ele é deslocalizado (KAISER, 1973:281-282).

Milton Santos partiu da concepção de Kaiser de região funcional para construir seu conceito, realçando uma de suas características: a grande influência de fatores externos. Contudo, Milton Santos não se contentou apenas em constatar esse fato. Ele procurou decifrar as razões econômicas 
mundiais que formam a região, que interferem, decisivamente, na produção de seus fluxos e de seus fixos.

Portanto, devem ser consideradas as divisões do trabalho precedentes que, no espaço, produziram fixos, instrumentos de trabalho ligados a diversas etapas do processo produtivo. Os fixos são concretizados conforme a lógica do momento de sua produção, mas, em contato com novas divisões do trabalho, podem se transformar conforme as novas necessidades externas. Assim, nos fixos socialmente criados, suas configurações não são apenas regionais. A cada momento histórico, a região torna-se o grande teatro de ações internacionais, modificando suas formas e estruturas.

Os fixos, que dão a uma área uma configuração espacial particular, são dotados de uma autonomia de existência, mas isso não elimina o fato de que eles não têm uma autonomia de funcionamento. Por isso, a região e o lugar são lugares funcionais do todo (SANTOS, 1985:68).

Considerando a dinâmica global e sua inserção nas regiões, algumas delas são capazes de receber novas ações e formas sem transformar a organização regional preexistente. Outras, por sua vez, são capazes de receber as novas ações externas e encontrar um novo arranjo que possa reproduzir as relações anteriores em conjunto com as novas. A senilidade dos fixos presentes na região não significa sua perda de valor no processo produtivo ou perda de capacidade de participar do processo de acumulação.

Assim, a região se definiria como o resultado de possibilidades nela presentes, geradas pelo capital fixo e pelas relações políticas, sociais e culturais. Os fixos, de fato resultados de uma razão técnica, jamais deixam de ter um conteúdo político. Refletir sobre a região, portanto, envolve a compreensão das relações entre as formas e seus conteúdos estabelecidos num determinado espaço, interagindo entre si (SANTOS, 1985).

Entretanto, as regiões comportam formas e conteúdos distintos no processo contraditório do capitalismo. O modo de produção não garante a homogeneidade das regiões. Ao contrário, ele instiga as diferenças como forma de produzir, em cada lugar, algum tipo de vantagem comparativa para a acumulação de capital. Quanto mais influências externas os lugares sofrerem, mais eles se tornarão singulares, únicos. Assim,

a região torna-se uma importante categoria de análise, importante para que se possa captar a maneira como uma 
mesma forma de produzir se realiza em partes específicas do Planeta ou dentro de um país, associando a nova dinâmica às condições preexistentes (SANTOS, 1988:47).

Ressalta-se, novamente, que para compreendê-la torna-se indispensável o entendimento de como a vida nela funciona, suas especializações, suas relações internas e seu arranjo particular em constante processo de mudança. Mas isso seria insuficiente sem a compreensão da totalidade do movimento que a condiciona. A região é o resultado do fluxo de ações internas e externas. Em outras palavras, para compreendê-la é preciso entender como ocorre a internalização dos processos externos, tendo em conta o que nela preexiste à chegada do externo, ou seja, sua história. Volta-se, então, para o jogo de relações entre o externo e o interno, ou seja, o conjunto de relações que fará com que um mesmo processo mundial de produção tenha diferentes resultados conforme cada lugar ou região (SANTOS, 1988).

A dinâmica da região é o produto de uma síntese desses dois conjuntos de fatores, externos e internos, em constante movimento de convergência e divergência. Os fatores externos exercem sempre influência ativa na região. Mas eles nem sempre coadunam com seus interesses. Por isso, as forças internas, quase sempre, desempenham uma função de oposição aos fatores externos, mesmo que a oposição não seja explícita.

Quanto à sua conformação histórica, cada região é resultado da combinação incessante de variáveis ${ }^{3}$ distintamente datadas, de vários tempos da divisão internacional do trabalho. Os tempos, de acordo com os lugares, tornam-se diferenciados uns dos outros devido às exigências da demanda externa e da própria lógica interna existente em cada região.

$\mathrm{O}$ processo de transformação da realidade regional, diante das demandas externas, ocorre não só nas relações mais comuns das regiões, mas também em seus processos mais complexos, que se revelam nas grandes transformações ocorridas no período técnico-científicoinformacional. Em uma região onde a composição orgânica do capital é alta e favorece a circulação de mercadorias, as trocas configuram um ambiente regional com alta capacidade produtiva, o que conduz à integração com outras regiões complementares. Nesse processo, o rural torna-se industrializado, objeto de ações capitalistas industriais,

\footnotetext{
${ }^{3}$ As variáveis, consideradas por Milton Santos, são: as tipologias da tecnologia do capital, da produção das firmas e das instituições; os circuitos de produção agrícola e da agroindústria; as relações de trabalho tanto no campo quanto na cidade. Essas variáveis só têm sentido se analisadas em conjunto, pois são interdependentes, uma sendo causa e, ao mesmo tempo, efeito da outra (SANTOS, 1985).
} 
transgredindo as antigas relações tradicionais agrícolas. As grandes cidades mimetizam suas áreas complementares, formando as regiões metropolitanas. Embora essas áreas não estejam, necessariamente, contíguas no território, estão conectadas pelas relações capitalistas urbanoindustriais. Mesmo as áreas agrícolas não atingidas diretamente pela modernização são incorporadas à dinâmica do processo pela migração campo-cidade e pelo consumo de produtos urbanos. "Do mesmo modo, a designação região agrícola muda de conteúdo. Áreas dedicadas à produção agrária, mas utilizando relativamente baixos coeficientes de capital, necessitam de aglomerações urbanas, fornecedoras de meios de consumo pessoal e produtivo" (SANTOS, 1985:69).

Segundo Milton Santos (1985), em termos de produção industrial e de serviços, a cidade exerce o papel de distribuidora de mercadorias indispensáveis à reprodução das áreas agrícolas. $\mathrm{O}$ que diferirá a região urbana da região agrícola será a densidade das relações mantidas no espaço. A noção de oposição entre campo e cidade ganha ares de complementaridade. O espaço urbano é complementar ao espaço rural. Há, porém, exceções, como os enclaves, zonas produtivas caracterizadas por elevada densidade de capital, que não estabelecem relações de complementaridade com seu entorno.

O conhecimento da região urbana exige, também, análise de sua estrutura interna, das articulações que regem seu funcionamento, de suas funções e estruturas. A estrutura interna permite conhecer a realidade de cada espaço e sua conexão com a totalidade do espaço.

A região, inclusive a urbana, na obra de Milton Santos, aparece, em princípio, como internalização do externo - em outras palavras, como um espaço funcional do modo de produção. Ela é o resultado de múltiplas variáveis externas em contato com a dinâmica local. Nesse encontro entre o interno e o externo, prevalecem as demandas do externo, do modo de produção global, sobre o fragmento do espaço, recorte vivo de lugar, a região.

A função da região imposta pelo modo de produção torna-a um espaço que se realiza a partir de necessidades exteriores a ela. Desse modo, a região apresenta certa fugacidade devido à velocidade dos fluxos de informação e de mercadorias a ela externas, e, por sua vez, seu edifício interno torna-se instável.

Milton Santos vê a região como consequência direta do processo de expansão e fragmentação do modo de produção capitalista, fruto da divisão do trabalho imposta pelos atores hegemônicos do mercado mundial. As análises regionais, então, passaram a ser compreendidas como derivações 
funcionais dos processos da economia global, e suas características internas colocadas em segundo plano. Porém, as desigualdades socioespaciais geradas pelo capitalismo constituem, apenas, uma faceta do fenômeno regional. Sua realidade interna não pode se resumir a mero resultado de funções atribuídas de processos gerais (LENCIONI, 1999).

A visão de região, como uma realidade espacial que não tem existência em si, que não se sustenta por falta de autonomia de sua dinâmica interna, fez com que autores como Castro (2002) e Gomes (1995) concluíssem que esse conceito, para Milton Santos, não era tão importante. À medida que a região se torna funcional e efêmera - e sua dinâmica nascida não de dentro, mas de fora, sendo assim incapaz de produzir uma identidade regional -, o conceito perde relevância analítica.

Contudo, o entendimento mais preciso do conceito de região em Milton Santos, segundo Castro, deve considerar a totalidade e o tempo histórico. Esses dois termos tornam mais clara a compreensão do conceito de região. $\mathrm{O}$ acontecer regional dependeria, assim, do acontecer social como um todo. Cada região representaria as necessidades e os anseios da sociedade em seu conjunto. As regiões seriam apenas áreas funcionais do todo, cuja essência dependeria do modo de produção.

Ainda segundo Castro, Milton Santos destaca a importância do recorte espacial para a compreensão do mundo contemporâneo que se fragmenta e se divide no processo de globalização. A expansão do capitalismo não eliminaria as diferenças regionais. Porém, a velocidade das informações e dos fluxos causaria o desmoronamento do edifício regional. A aceleração do tempo histórico remodela todo o recorte espacial, e o mundo se redefine, redefinindo as regiões e os lugares. Nessa perspectiva, a região continuaria sendo um espaço conveniente ao capitalismo em expansão, um espaço funcional. Castro sintetiza sua visão dos problemas da análise de Milton Santos sobre a região:

Em primeiro lugar, a perspectiva do fenômeno regional como resultado de uma determinação do alto, o que estabelece por definição uma impossibilidade ontológica de qualquer nível explicativo do recorte regional. Neste caso não é possível falar de uma natureza do fenômeno regional, uma vez que o fenômeno real é o modo de produção. A região seria então apenas um epifenômeno. Em segundo, a exigência do recorte regional ser definido pela funcionalidade dos fenômenos, ou eventos, que podem ser breves (CASTRO, 2002:3). 
Essa visão de região funcional levou o autor a abandonar a possibilidade interpretativa do conceito de região segundo parâmetros internos a ela. A ênfase na noção de totalidade, para Castro (2002) e Gomes (1995), impossibilitou Milton Santos de pensar, ontologicamente, a região como um espaço com vida própria. Dessa maneira, o conceito tornou-se inútil para explicar as diferenças espaciais, permanecendo apenas como uma referência para indicar um recorte analítico do espaço.

Já Cunha, Simões e Paula (2005), apoiados nos argumentos de Castro, afirmam que não procede o conceito de região proposto por Milton Santos, dada a falta de características internas a ela. Para esses autores, a formação econômica e social é apresentada como a totalidade da vida social, e as particularidades, somente, como um nível dessa totalidade. Além disso, a totalidade espacial emerge como núcleo fundante dos lugares e das regiões que se transformam em meros subespaços subordinados à totalidade. Cada acontecer social particular representaria apenas uma determinação do universal, do modo de produção capitalista.
O conceito de região em Milton Santos não só estaria dissolvido pelo foco na inserção do local no total, como cerceado pela literatura da funcionalidade a orientar o recorte, intimamente preso assim à dinâmica dos processos sócio- econômicos (CUNHA, SIMÕES e PAULA, 2005:16).

$\mathrm{O}$ conceito de região em Milton Santos se esvaziaria porque, a partir dele, a região apenas poderia ser entendida no contexto do movimento externo que a produz, o que impediria sua compreensão ontológica, ou seja, o entendimento de sua razão de ser contida em si.

Os autores citados ressaltam a importância de compreender a superposição de recortes e a fragmentação dos espaços como fatores fundamentais para a formação das regiões. A análise da geografia crítica, assim como a de Milton Santos, pecaria por manter um enfoque essencialmente no presente, e não na formação histórica.

Como se afirmou, a geografia crítica oferece um território fértil para se pensar as relações entre espaço e história, mas no que diz respeito à região, não se pode buscar transposições conceituais diretas, particularmente por conta do foco incisivo desta corrente no tempo presente e no modo de produção capitalista (CUNHA, SIMÕES e PAULA, 2005:17).

A ênfase na reprodução capitalista, no entendimento da região e das diferenciações dos recortes espaciais, limitaria o conceito a uma 
temporalidade específica, a sociedade de mercado (CUNHA, SIMÕES e PAULA, 2005). Ao contrário, a análise do presente, na perspectiva da geografia crítica, não elimina o passado, somente estabelece a premissa de que é a partir do presente que se inicia o processo de compreensão do passado. A partir da realidade do mundo contemporâneo, Milton Santos (1978) considera os conceitos de região geográfica de La Blache e de região natural como categorias do passado. Para ele, quando as categorias não condizem mais com a realidade contemporânea, seus conteúdos deverão ser revistos.

Haesbaert (1999a) chama a atenção para o entendimento da região como uma manifestação espacial de um recorte vivo: ela não pode se perder na visão de um objeto autossuficiente a ser descoberto (La Blache), nem, tampouco, ser considerada um recorte espacial a priori, definido pelo pesquisador conforme seus objetivos e critérios (Hartshorne). A região não deve ser vista apenas como uma ideia, um conceito, mas como uma realidade, uma construção humana. Se o conceito nunca esgota as possibilidades do mundo, muito menos o substitui, ele, porém, participa dessa realidade à medida que sua elaboração acaba sempre interferindo na leitura do pesquisador e em sua ação sobre o mundo.

Lencioni (1999) também critica o conceito de região proposto por Milton Santos, assim como pela geografia crítica. Para a autora, a dimensão do vivido e do percebido está, quase sempre, ausente no debate da geografia regional de cunho marxista. Tratar os lugares a partir de seus significados e de suas representações traz à tona a importância de compreender o que se passa dentro das regiões, observando como as pessoas vivem o dia a dia desse espaço.

De acordo com Frémont (1980), para compreender a relação direta do homem com seu espaço é preciso realçar que ela gera um sistema particular que une os homens a seu território. O homem não é um objeto neutro na região - ele apreende o espaço que o cerca e o sustenta de maneira diversa. Ele emite juízos, valores, é atraído ou repelido pelo espaço, consciente ou inconscientemente. A racionalidade perturba-se nessa relação subjetiva entre o homem e o espaço; os hábitos cotidianos, as afetividades, as culturas e o inconsciente transformam a região. $\mathrm{O}$ espaço vivido, então, surge, com toda a sua complexidade, revelador de identidades regionais que apresentam, certamente, componentes históricos, econômicos, políticos, culturais, naturais e psicológicos.

A região, se existe, é um espaço vivido. Vista, apreendida, sentida, anulada ou rejeitada, modelada pelos homens e projetando neles imagens que os modelam. É um reflexo. 
Redescobrir a região é, pois, procurar captá-la onde ela existe, vista pelos homens (FRÉMONT, 1980:17).

A análise do espaço vivido pode permanecer, apenas, nas representações, ficando somente na aparência do fenômeno, omitindo sua essência. Dar ênfase ao heterogêneo, à diferença, à subjetividade, fugindo às influências gerais, poderia causar a atomização, a individualização dos fenômenos e da região. Poderia significar, até, a volta às monografias regionais que se constituíam no início do século passado e que se resumiam à descrição das relações entre a natureza e os homens presentes num determinado espaço, tornando-o único, singular (LENCIONI, 1999).

Essa perspectiva fragmentante da realidade, que atribui autonomia analítica às regiões, afasta-se da noção de interdependência entre as partes e o todo, entre o particular e o universal, comprometendo uma reflexão condizente com o mundo, cada vez mais conectado por redes e fluxos de informação cultural, política e econômica.

Haesbaert (1999a) também coaduna com a perspectiva do conceito de região na vertente marxista. Porém, ele não se esquiva de pensar o espaço vivido, sem deslizar sua análise na atomização da região. Seu objetivo é juntar o que, para muitos, é o disjunto, ou seja, unir no mesmo conceito as determinações do capitalismo global à produção das identidades regionais.

$\mathrm{O}$ autor reconhece, por outro lado, que a vertente marxista na geografia recuperou, para os estudos regionais, a noção de divisão territorial do trabalho como fundante das desigualdades socioespaciais. Qualquer iniciativa de analisar a diversidade e desigualdade regional implica reconhecer a inter-relação entre particular e geral, entre universal e singular. Mas não significa corroborar uma visão global determinista, como ocorre com aqueles que fazem do comportamento da economia internacional o único fator explicativo das segmentações espaciais. Nem, muito menos, perder-se em estudos específicos, sem conexão com o mundo, o que remete à romantização da região, como espaço de harmonia e de identidade.

Cabe a uma Geografia Regional renovada recuperar o sentido dos recortes espaciais tanto a partir de sua inserção desigual em movimentos mais globalizados quanto a partir de recriação de singularidades que lhes dão um caráter próprio. Revalorizar o singular não significa cair outra vez numa fenomenologia pura, que vê somente o acontecimento, ou num empirismo bruto, baseado no binômio observação- 
descrição; significa, isto sim, evidenciar a capacidade dos grupos humanos de recriar espaços múltiplos de sociabilidade (HAESBAERT, 1999a:22).

Para entender a diversidade regional, segundo Haesbaert, é preciso não priorizar a desigualdade em face das diferenças regionais, o geral em face do particular. As escolas geográficas que pensaram a questão regional ora se baseavam na diversidade regional, no sentido de particularidades e das diferenças espaciais, ora se pautavam na perspectiva da desigualdade fomentada pela divisão internacional e territorial do trabalho.

O principal desafio da geografia regional é aliar a análise sistêmica das desigualdades à produção da diferença, da vivência do espaço singular, da identificação com o espaço (HAESBAERT, 1999a). Há, assim, duas dimensões que se completam: uma que corresponde ao singular, ao específico, ao que acontece e se vive em cada lugar; outra, mais totalizante, que compreende o processo de regionalização a partir das desigualdades formadas pelo capitalismo em processo de expansão. Essa visão integrada servirá para reconhecer as especificidades de cada região e, ao mesmo tempo, entender que elas estão interligadas umas às outras no movimento da totalidade. A análise da região em Haesbaert aponta para um caminho diferente, em princípio, do que se observa em Milton Santos.

\section{A metamorfose de região em lugar na obra de Milton Santos}

Refletir sobre a região implica não somente a compreensão da produção e da circulação de coisas e de objetos em seu espaço, mas também o entendimento da criação de resistências, de desejos, de vontades que correspondem às necessidades e carências específicas de cada lugar, que podem estar conectadas às necessidades e carências de outros lugares. A compreensão dos conceitos de produção e reprodução social enriquece a reflexão sobre a região, à medida que se percebe que ela está ligada ao mundo, não só pelo processo produtivo, mas também pelo processo de reprodução social. A região produziria e criaria suas especificidades conforme suas particularidades históricas e culturais.

A concepção de Milton Santos sobre a região, entretanto, ao contrário do que fez parecer até então, não se resume à funcionalidade do modo de produção, ou ao recorte espacial, que depende da ampliação e da circulação da mais-valia e da produção capitalista. A análise e a crítica estabelecidas pelos autores mencionados correspondem à concepção restrita de região. Sem o entendimento do desenvolvimento do conceito ao 
longo de sua obra, não se podem compreender suas transformações e a amplitude que o conceito assume.

A partir do livro A natureza do espaço, percebe-se a metamorfose do conceito de região em conceito de lugar - espaço do singular, espaço de convergência e divergências dos vetores da modernidade, espaço funcional do todo, mas também espaço de criação de novas formas de vida e de novas práticas socioespaciais. Milton Santos retorna ao conceito de região, para a análise do mundo contemporâneo, como um espaço que comporta a realidade do local, do vivido, do qual parte para compreender o movimento do mundo, retornando ao lugar, espaço da prática social. Ele recupera o movimento da totalização dos processos socioespaciais que compõem tanto a região ou o lugar quanto o espaço. ${ }^{4}$ Várias passagens de sua obra mostram essa metamorfose do conceito de região em lugar.

\begin{abstract}
(...) a palavra lugar é, como outras do vocabulário geográfico, prenhe de ambiguidades, já que a região é, também, um lugar e a própria expressão região serve para designar extensões diferentes. Sabemos a priori que a dimensão geográfica do tempo mais externo é o mundo, mas não sabemos qual a extensão do tempo mais interno. Ainda que um método laboriosamente estabelecido pudesse permitir, a posteriori, reconhecer esse tempo interno mais pequeno, tal constatação não seria absoluta (SANTOS, 1997:111).
\end{abstract}

Milton Santos reconhece que cada lugar é alvo de tempos externos variados, e a partir desse tempo do mundo se configura o tempo do lugar. Para sua ação, os homens tiram proveito das possibilidades oferecidas pelo mundo, mas é só a partir do lugar que eles se tornam efetivos. A região e o lugar são espaços, recortes do mundo em movimento, e somente por essa inserção é que se pode compreender a dinâmica do lugar ou da região. Porém, é pelo lugar que o movimento do mundo é percebido. "Mas, nos dias atuais, os lugares são condição e suporte de relações globais que sem

\footnotetext{
${ }^{4}$ Corrêa (1997) e Lencioni (1999) acreditam que a região é uma mediação entre o lugar e o espaço. Para ambos, a região seria um espaço dinâmico, uma fragmentação articulada com os processos gerais, nos quais a globalização não dotaria a região de autonomia. Mas essa análise não se limitaria à influência do capital externo na formação da região. Ela leva em conta como se reproduzem essas relações capitalistas nas especificidades regionais e como são geradas, a partir de dentro, novas formas de lidar com a complexidade do mundo contemporâneo. Mas, na concepção de Milton Santos, a região seria sinônimo de lugar, e a mediação entre ela e o espaço se daria a partir do território usado, e não da região. O território, para o autor (1994b, 2000b), seria a mediação necessária entre o particular e o universal.
} 
eles (lugares) não se realizam" (SANTOS, 1999:16). As regiões, sinônimos de lugares, tornaram-se espaços convenientes do capital global, lugares onde se efetivam as necessidades do capital hegemônico - mas também espaços do vivido, das relações sociais solidárias e compartilhadas.
A região e o lugar não têm existência própria. Nada mais são que uma abstração, se o considerarmos a parte da totalidade. Os recursos totais do mundo ou de um país, quer seja o capital, a população, a força de trabalho, o excedente, etc., dividem-se pelo movimento da totalidade, através da divisão do trabalho e na forma de eventos. A cada momento histórico, tais recursos são distribuídos de diferentes maneiras e localmente combinados, o que acarreta uma diferenciação no interior do espaço total e confere a cada região ou lugar sua especificidade e definição particular. Sua significação é dada pela totalidade de recursos e muda conforme o movimento histórico (SANTOS, 1997:131).

A região e o lugar são espaços gerados por um movimento geral do mundo. Nesses espaços, o tempo do mundo entra como condição de possibilidade e o tempo do lugar como condição de efetividade. A cada nova modernização do mundo, os lugares sofrem modificações, desestabilizando sua dinâmica interna e criando novas formas de ações sobre eles.

Nessas circunstâncias, a distinção entre região e lugar passa a ser menos relevante, pois não corresponde ao que há de mais importante na definição de ambos: a unidade e a continuidade do acontecer histórico e solidário, a contiguidade no espaço de práticas de vizinhança e de solidariedade. Vislumbra-se a identidade entre região e lugar, podendo-se defini-los como espaços do acontecer solidário. Os lugares, as cidades são, cada vez mais, regiões (SANTOS, 1997).

Balbim corrobora a opinião de que o conceito de região se transforma no de lugar:

A região (...) assemelhar-se-ia ao lugar que propõe Milton Santos. A região abrigaria não apenas um conjunto de sinais de um jogo político, mas a multidimensionalidade do ser. Ou seja, ao mesmo tempo, o ser vivendo o processo de produção territorial e o produto territorial - expresso entre outras formas pela região - de um sistema de relações existenciais e/ ou produtivas (BALBIM, 2001:164). 
Essa transformação conceitual da região em lugar abre caminho para perceber que o conceito de região em Milton Santos se amplia no sentido proposto por Lefebvre. O recorte espacial comporta as determinações do modo de produção, as relações socioespaciais de produção e, também, a criação de obras, de identidades, de subjetividades e de desejos. É nessa dialética do externo e do interno, do universal com o particular, que se desenvolve, no autor, a metamorfose do conceito de região em conceito de lugar.

\begin{abstract}
Qualidade e quantidade são categorias do extenso ou do espaço porque o extenso é espaço. É nesse sentido que não há como distinguir, do ponto de vista analítico, a região do lugar. Região e lugar são a mesma coisa. No passado perdemos muito tempo mostrando a diferença entre lugares, áreas e pontos (SANTOS, 2003:62).
\end{abstract}

A região reaparece, em Milton Santos (2003), como lugar do acontecer solidário, aquele previsto por Durkheim, de trabalho e espaço compartilhados, de realização compulsória de tarefas em comum, mesmo que os objetivos das pessoas envolvidas não sejam os mesmos. $\mathrm{O}$ acontecer solidário dá nova configuração à região: ela deixa de ser um recorte geométrico para ser uma extensão social compartilhada, de vizinhança e de copresença.

Nas regiões agrícolas, o acontecer é homólogo; nas relações entre cidade e campo, ele é complementar, mas, numa cidade dominada por uma especialidade produtiva, o acontecer pode, também, tornar-se homólogo. Há, por fim, o acontecer hierárquico quando um lugar está sob ordens e informações provenientes de outro lugar. "Não é que haja um lugar comandando o outro, senão como metáfora. Mas o limite à escolha de comportamento num lugar pode se dever aos interesses sediados em um outro" (SANTOS, 2002:158).

O acontecer hierárquico pressupõe, de acordo com Milton Santos (2002), tipos de relações pontuais, descontínuas no espaço, que criam funções e normas para as práticas produtivas ou cotidianas das regiões. Tanto o acontecer homólogo quanto o complementar correspondem a uma continuidade de relações sociais numa extensão espacial, cuja solidariedade une as regiões.

A ideia de região e de lugar é, na verdade, uma consequência de dois recortes espaciais: o das horizontalidades, correspondente ao acontecer homólogo e complementar, e o das verticalidades, correspondente ao acontecer hierárquico. Da horizontalidade faz parte o 
conjunto de firmas, instituições, trabalhos que habitam um extenso, uma área contínua. A verticalidade é a relação entre pontos dispersos no espaço, pontos descontínuos interligados pela técnica e pela informação, que recebem ordem e a executam conforme necessidades estranhas ao lugar (SANTOS, 1997). As horizontalidades se assemelham à noção clássica de região, onde predomina uma solidariedade orgânica, e as verticalidades correspondem à noção moderna de região funcional.

As horizontalidades aglutinam as ações de fora com as solidariedades criadas no lugar. Elas são "o teatro de um cotidiano conforme, mas não obrigatoriamente conformista, simultaneamente, o lugar da cegueira e da descoberta, da complacência e da revolta" (SANTOS, 1997:227). Ela comporta uma força centrípeta que liga o processo econômico ao social, convergindo no lugar. Já a verticalidade contém uma força centrífuga que causa a desagregação do espaço e das pessoas. Entre os fatores da verticalização, encontram-se o comércio internacional, as demandas das multinacionais e do capital financeiro, os quais, juntos, trazem outras ordens aos lugares, tornando-os, cada vez mais, dependentes do processo de mundialização do capital. Mas os lugares podem, também, reconstituir-se horizontalmente, a partir de ações que fortifiquem os traços de união da sociedade. Esses traços valorizam, no espaço do cotidiano, a solidariedade orgânica (SANTOS, 1997).

A tendência atual é a de que os lugares se unam verticalmente e tudo é feito para isso, em toda parte. Créditos internacionais são postos à disposição dos países mais pobres para permitir que as redes modernas se estabeleçam ao serviço do grande capital. Mas os lugares também se podem unir horizontalmente, reconstruindo aquela base de vida comum, susceptível de criar normas locais, normas regionais... que acabam por afetar as normas nacionais e globais (SANTOS, 1997:206).

Através das horizontalidades se reconstituem as identidades regionais. No mundo da velocidade e do efêmero é de se supor que a solidariedade organizacional vá se sobrepor à solidariedade orgânica na região. Mas a solidariedade orgânica impõe limites à solidariedade organizacional. Ela é desejada pelas pessoas que querem viver compartilhando o espaço vivido. Assim, a identidade construída lentamente na antiga região cede lugar à possibilidade de futuro, a partir de práticas comuns realizadas nos espaços banais, nas zonas opacas, nos lugares aonde os vetores da modernidade chegam lentamente (SANTOS, 1997). 
A identidade é, dessa maneira, uma construção social apreendida pela percepção e pela apropriação simbólica e material do espaço e da região. Identificar-se é sempre um processo de identificação com outra pessoa e um lugar, uma busca por relacionamentos e alteridades que se dão no encontro ou no desencontro. Por isso, a identidade é sempre um processo relacional entre pessoas e lugares, isto é, um processo socioespacial (HAESBAERT, 1999b).

A identidade é, contudo, um processo. $\mathrm{Na}$ globalização, as identidades são cada vez mais descontínuas, fragmentadas, sobrepostas. A todo evento, surgem novas formas de identificação propiciadas pelo conflito ou pela solidariedade. Cada sujeito assume várias identidades em momentos diferentes de sua vida. Identificar-se é estar sempre em movimento no espaço e no tempo. Segundo Hall (2004:13), "dentro de nós há identidades contraditórias, empurrando em diferentes direções, de tal modo que nossas identificações estão sendo continuamente deslocadas".

A visão romântica de comunidade tradicional, fortemente estruturada no lugar, perde sentido à medida que os lugares, na contemporaneidade, podem conter várias comunidades e identidades. Nesse sentido, o lugar é um híbrido, palco de transformação constante, de convergência e divergência incessante de múltiplas identidades (HAESBAERT, 1999b).

O lugar é o espaço de múltiplas identidades, onde se encontra e se entrelaça uma multiplicidade particular de relações socioespaciais. O lugar receberia, com sua estrutura própria, constantemente, ações que partem do exterior, e com elas interagindo. Segundo Milton Santos (1997:273), "cada lugar é, ao mesmo tempo, objeto de uma razão global e de uma razão local, convivendo dialeticamente". Os lugares são alvos de uma lógica global, de verticalidades e que, ao mesmo tempo, contêm uma lógica local, as horizontalidades.

Mas, conforme o autor, há a presença de outras formas de convivência. Ele denomina contrarracionalidade essa nova forma de discurso, contrapondo à racionalidade instrumental. Em suas palavras, as contrarracionalidades "são formas de convivência e de regulação criadas a partir do próprio território a despeito da vontade de unificação e homogeneização, características da racionalidade hegemônica típica das verticalidades" (SANTOS, 2000a:110).

A região ou o lugar podem ser compreendidos, ainda, pelas esferas da vida que se completam, isto é, pela psicoesfera e pela tecnoesfera. A tecnoesfera representa a crescente artificialização do meio ambiente, na qual a natureza é substituída pela técnica, fruto do progresso da ciência e 
da tecnologia. A psicoesfera é o resultado da subjetividade, dos desejos, das crenças e das vontades quando, então, percebe-se o estímulo ao comportamento prático e, também, filosófico (SANTOS, 1994a).

A tecnoesfera se adapta às necessidades externas, pois é regida pelos mandamentos da produção e da troca. Já a psicoesfera é o campo da emoção, da subjetividade, das ideias, das crenças. Tanto a psicoesfera quanto a tecnoesfera se constituem no lugar, mas suas razões, suas normas, seus comandos nem sempre se resumem ali, naquele espaço.

A partir da tecnoesfera e da psicoesfera, podem-se definir os lugares segundo suas densidades técnica, informacional e comunicacional. Quanto maiores as inovações tecnológicas, a ciência aplicada à produção e à informação, maiores serão as densidades técnica e informacional e suas dependências da conjuntura internacional. A densidade comunicacional, por sua vez, representa o caráter social da ação, a práxis intersubjetiva, o tempo plural do acontecer solidário. Para a compreensão das ações, não se pode deixar de considerar a intersubjetividade presente na comunicação durante o processo de interação dos homens (SANTOS, 1997).

As duas primeiras [densidades técnica e informacional] são mais dependentes da esfera da materialidade, da tecnoesfera, as últimas [densidades comunicacionais] o são mais da esfera da imaterialidade, mesmo se, em todos os casos, tecnoesfera e psicoesfera se interagem. (...) Nas condições atuais, as relações informacionais transportam com elas o reino da necessidade enquanto que as relações comunicacionais podem apontar para o reino da liberdade (SANTOS, 1997:206).

Milton Santos (1997) estabelece a distinção entre informação e comunicação. Os seres humanos podem estabelecer uma comunicação entre eles conforme o mundo que compartilham entre si, sem, contudo, precisar de qualquer tipo de informação. Também podem transmitir informações, sem criar qualquer interatividade com o lugar que informa. Comunicar significa pôr em comum, dialogar com diversas interpretações do mundo (alteridade), pôr em diálogo seus anseios e necessidades, expondo seus pontos de vista à procura do bem comum. O mundo e o lugar ganham sentidos a partir da alteridade e da comunicação. Por outro lado, informar significa circular ideologias, mercadorias, ideias, imagens, que não precisam, necessariamente, ser apreendidas ou compreendidas, conscientemente, pelas pessoas.

A comunicação, segundo Milton Santos (1997), requer a proximidade, a coexistência na diversidade. A proximidade que se refere à 
contiguidade das relações humanas no espaço, numa mesma extensão, num segmento de pontos contínuos. Uma proximidade que agrupa as pessoas pela prática cotidiana, em que todos, ou quase todos, se reconhecem na vivência de cada um.

A partir da ideia de proximidade, torna-se mais próxima a compreensão das questões relativas à vizinhança e à comunicação. Tais questões se identificam com a noção de densidade social: proporção de pessoas que compartilham o mesmo espaço. A quantidade de pessoas no lugar pode provocar mudanças, transformações que ressuscitam afetividades, paixões, subjetividades e compaixões (SANTOS, 1997).

O lugar pode ser, portanto, o espaço da resistência às normas globais, o espaço de contrarracionalidades capaz de construir novas formas de convívio que comportem a solidariedade, a tolerância e a comunicação.

Na realidade, cada lugar, à sua maneira, é o mundo, mesmo que em potencialidade. Cada lugar imerso no mundo também se torna diferente dos demais. Para compreender o lugar, não se deve contentar apenas com uma reflexão sobre o local, e sim buscar o mundo no lugar. A história do presente faz do lugar o conceito fundamental para a compreensão do movimento do mundo, mas também para a prática social (SANTOS, 1997).

O lugar se opõe ao mundo, mas também se confunde com ele. Em sua essência, o mundo contemporâneo, globalizado, pode se esconder, mas, no lugar, ele se expõe. No lugar se sobrepõem os tempos externos dos atores hegemônicos e o tempo interno da coexistência. Nele se fundem os diversos vetores da modernidade com os vetores do próprio lugar. No lugar, o recôndito e o que permanece triunfam sobre o efêmero, sobre o passageiro. O lugar é o espaço que acolhe o novo, mas que resiste às mudanças (SANTOS, 1997). Nele se guardam a cultura, a sociabilidade, a vizinhança, a solidariedade e a resistência. Sua importância é destacada por Milton Santos:

Tudo começa com o conhecimento do mundo e se amplia com o conhecimento do lugar, tarefa conjunta que é hoje tanto mais possível porque cada lugar é o mundo. É daí que advém uma possibilidade de ação. Conhecendo os mecanismos do mundo, percebemos por que as intencionalidades estranhas vêm instalar-se em um dado lugar, e nos armamos para sugerir o que fazer no interesse social (SANTOS, 1994a:117).

O lugar, espaço do cotidiano, é compartilhado por diversas pessoas, firmas e instituições, formando uma base de cooperação, mas também de 
conflito. A solidariedade se realiza como uma prática de comunhão no lugar, ali onde a política se realiza como dissenso entre organização e espontaneidade. $^{5}$

Para Lefebvre (1991a), não se pode dissimular o cotidiano referindo-se apenas ao repetitivo, ao monótono. Trivialmente, o cotidiano contém repetições, gestos de trabalho, gestos fora do trabalho, mecanicismo e automação das mãos, do corpo, da fala, repetições lineares e cíclicas, tempo da natureza e da racionalidade instrumental. Para o autor, o estudo da atividade produtiva induz à análise de sua reprodução, à maneira como a produção se autorreproduz na realidade cotidiana. Por isso, a análise do cotidiano não pode se resumir em sua singularidade, sua especificidade. Ela tem de ser dialeticamente relacionada com o mundo que a produz.

O cotidiano pode aparecer como uma suposta rotina, mas ele é, na verdade, um complexo de momentos compostos por tempos de trabalho e de diversão; de passividade e de criatividade; de meios e de fins, numa interação dialética que, sucumbida, perde a perspectiva do possível, da emancipação humana. ${ }^{6}$

O espaço do cotidiano, que, aparentemente, é o lugar da reprodução e da alienação no âmbito do vivido, pode ser, também, o lugar das possibilidades contidas nos homens e nas coisas, da oposição à sociedade

5 "O lugar é o quadro de uma referência pragmática do mundo, do qual lhe vêm solicitações e ordens precisas de ações condicionadas, mas é também o teatro insubstituível das paixões humanas, responsáveis, através da ação comunicativa, pelas mais diversas manifestações da espontaneidade e da criatividade" (SANTOS, 1997:256).

${ }^{6}$ Para Heller (s.d.), a vida cotidiana é aquela esfera da vida que mais se presta à alienação (a separação do ser de suas possibilidades de desenvolvimento enquanto ser genérico, social). Na vida cotidiana, parece natural a separação entre ser e essência. O homem inserido na cotidianidade se contenta em representar seu papel predeterminado na reprodução social, sua margem de manobra, sua válvula de escape acaba reproduzindo as relações sociais de produção. A representação do papel de reprodutor das relações sociais pode resultar num conformismo perante a vida, a falta de conflitos. É a vida monótona que reforça mais ainda a conformidade. A autora ressalta, porém, assim como Lefebvre (1991a), que a vida cotidiana pode ser, também, um terreno propício, uma brecha, uma fenda que permite aos indivíduos um movimento, uma possibilidade de explicação e ação no mundo. Dessa forma, a experiência do cotidiano torna o sujeito consciente de sua condição cindida (ser e essência). Para o indivíduo, ser genérico e social, a vida cotidiana passa a se manifestar como essência unitária de formas heterogêneas, como possibilidade de encontro e de desenvolvimento do ser e de sua essência. 
das mercadorias, da reivindicação de um mundo melhor (LEFEBVRE, 1991a).

O cotidiano, para Milton Santos $(1996,1997)$, no mesmo sentido, será a fábrica da desalienação, será o espaço no qual acontecem os preconceitos, a alienação, as relações sociais e sua reprodução e, ainda, a descoberta, a reivindicação, a vizinhança e a solidariedade.

Segundo Milton Santos (1996), existem três dimensões humanas que ajudam a compreender o cotidiano: a corporeidade, a individualidade e a socialidade. A corporeidade é a realidade do corpo do homem, sua forma, sua capacidade de movimento, de estagnação, de se localizar. A individualidade está relacionada à subjetividade do homem, à consciência dos homens, à consciência de si, à consciência do lugar que ocupa. A relação entre indivíduos representa a produção de socialidade, a terceira dimensão humana do cotidiano.

A condição de estar junto e habitar o mesmo espaço causa transformações na espacialidade e, consequentemente, na corporeidade e na individualidade. As dimensões do cotidiano têm, por conseguinte, fortes implicações espaciais e temporais. O cotidiano supõe o passado como herança e o futuro como possibilidade. O presente é este embate entre o passado e o futuro, a existência de um passado irreversível e de um futuro que oferece alternativa pelo simples fato de que ainda está por vir. O passado e o futuro carregam a necessidade e a liberdade, carregam o que somos e o que queremos ser, a dificuldade de se afirmar no mundo e no lugar e a esperança de construir outras possibilidades de existência no lugar e no mundo (SANTOS, 1996).

O cotidiano possui outras características, como a materialidade e a imaterialidade. O cotidiano é a materialidade que nos cerca e, também, a imaterialidade, presente nos objetos e nas ações, que nos constrange. Por materialidade, pode se designar a tecnoesfera; por imaterialidade, psicoesfera (SANTOS, 1996).

Para Milton Santos (1997), no cotidiano é resgatada a razão de viver por meio da contrapartida à racionalidade hegemônica. $\mathrm{O}$ mundo do cotidiano é o espaço que limita essa racionalidade e cria outras, tão diversas quantos são os lugares da existência humana. O cotidiano pressupõe uma busca por política, que resulte numa convergência de múltiplos interesses. Por isso, a vida cotidiana abarca várias temporalidades diferentes que se instalam em cada lugar, o que permite vislumbrar uma vivência compartilhada e solidária. A globalização anuncia que o mundo real busca uma homogeneização empobrecedora, mas esbarra no universo do cotidiano, no mundo da diversidade criadora. 
Por fim, o cotidiano é, também, o espaço da escassez. Ela se materializa, no cotidiano, nas necessidades de sobrevivência que aumentam a cada dia. A escassez de um pode ser a mesma escassez do outro. É nessa percepção que nascem a compaixão, a solidariedade, a compreensão das dificuldades do outro a partir de sua própria dificuldade, o sentimento de pertencer ao mesmo lugar e ter as mesmas carências e anseios. Assim, a alteridade no lugar favorece a criação de múltiplas possibilidades e identidades. Quanto mais diferentes forem as pessoas, mais ideias de mundo poderão frutificar (SANTOS, 2000a).

\section{A cidade: o espaço da confluência da região e do lugar}

Para Milton Santos (1997), a cidade é o lugar da multiplicidade de formas de escassez e de abundância, onde se revelam e se proliferam a pobreza e a riqueza. Para os pobres, ${ }^{7}$ a escassez é um fato concreto da existência, que os põe em contato diário com a realidade do lugar e do mundo, mas também os faz mudar de atitude conforme suas necessidades.

Aliás, uma das consequências da globalização e da escassez material e espiritual é o ressurgimento da cultura popular, ${ }^{8}$ que rivaliza com a cultura de massa. Trata-se da produção de uma resistência emergente na própria massa, mas que não contribui para sua alienação; ao contrário, divulga a escassez, a carência e as possibilidades percebidas no cotidiano, que permitem vislumbrar uma vida melhor (SANTOS, 2000a). Afinal, o cotidiano não é o movimento estruturado e coeso - ele é o mundo do lugar em movimento, um tecido flexível de relações em constante mutação, dependendo de suas necessidades diárias.

No fundo, a questão da escassez aparece outra vez como
central. Os de baixo não dispõem de meios (materiais e
outros) para participar plenamente da cultura moderna de
massa. Mas sua cultura, por ser baseada no território, no

${ }^{7}$ Segundo Milton Santos (2003), não se pode confundir pobreza com miséria. A miséria é a privação total, é a entrega, a derrota perante a vida. Já os pobres são carentes de toda ordem, mas não se entregam - lutam, tomam relativa consciência do mundo e se articulam, buscam um futuro possível.

8 “A cultura popular tem raízes na terra em que se vive, simboliza o homem e seu entorno, encarna a vontade de enfrentar o futuro sem romper com o lugar, e de ali obter a continuidade, através da mudança. Seu quadro e seu limite são as relações profundas que se estabelecem entre o homem e seu meio, mas seu alcance é o mundo" (SANTOS, 1997:262). 
trabalho e no cotidiano, ganha a força necessária para deformar, ali mesmo, o impacto da cultura de massa (SANTOS, 2000a:144).

A imposição de uma cultura de massa corresponde aos anseios de atores hegemônicos, enquanto a cultura popular é fruto de uma copresença no lugar, de um sentimento compartilhado de escassez e carência, mas que não se abala ao propor novas formas de viver. A cultura popular, conforme Milton Santos (2000a), põe em evidência o cotidiano da população pobre, dos marginalizados, expõe suas carências e anseios. Ela é a forma de expressão que caracteriza a busca por uma política mediante o discurso do lugar, revelando as idiossincrasias do mundo.

Certo é que o mundo se instala nos lugares, sobretudo, nas grandes cidades, nas metrópoles, provido de uma mistura de culturas, identidades e modos de vida, originários de todos os lugares do mundo. Todos trazem consigo seu passado e sua expectativa em relação ao futuro, à medida que vivem em conjunto, entre seus vizinhos, entre pessoas identificadas com as carências e os anseios dos demais, que enriquecem o cotidiano. "As dialéticas da vida nos lugares, agora mais enriquecidas, são paralelamente o caldo de cultura necessário à proposição e ao exercício de uma nova política" (SANTOS, 2000a:173).

A cidade é o espaço da mobilidade e do deslocamento, mas também da permanência e da inércia. Nas cidades, encontram-se a solidariedade e a coabitação, ambas mediadas pela estrutura preexistente: as rugosidades. As ações nas cidades são limitadas pelas formas e pelas normas de utilização dessas estruturas preexistentes, o que não impede a presença de uma vida cultural que subverta suas formas e suas normas.

A cultura popular reaparece, nessas circunstâncias, como condição e como possibilidade de novos usos do espaço. Ela passa a existir como criação. Assim, nascem novas maneiras de apropriação do espaço com as criações culturais populares, alimentadas por uma crítica à sociedade hegemônica, que brotam, espontaneamente, do cotidiano repetitivo e alienante. Mesmo que na prática não haja uma coesão entre os discursos de cada lugar, há vontade e, mais do que isso, possibilidade e necessidade de mudança (SANTOS, 1997).

Afinal, a cidade é o lugar onde o mundo se movimenta. A copresença traz a convivência entre as diferenças. Logo, quanto maior a cidade, tanto maior será o contato com as diferenças, mais vasta e densa será a copresença e o acontecer solidário. Nessa medida, as cidades são os lugares da revolta, do encontro improvável, já que nelas o novo se impõe com maior dificuldade do que no campo. A revolta deverá acontecer contra 
a situação social desigual, e não contra as formas, as coisas, as máquinas. Desse modo, é necessário o entendimento das formas para que se possam construir alternativas, mas a causa da situação atual se encontra por trás delas, nas relações sociais de produção que, em conjunto com as formas, constituem o espaço (SANTOS, 1994a).

Todavia, com o processo de globalização, todos os lugares se mundializam, uns mais do que outros. Por isso, Milton Santos os distingue por meio de dois conceitos: os lugares globais simples e os lugares globais complexos. Estes últimos podem ser o espaço da metrópole, onde os múltiplos vetores da modernidade convergem e, ao mesmo tempo, divergem, lugar da profusão de normas e funções externas, mas também de atores que se opõem à ação hegemônica.

Por isso a cidade grande é um enorme espaço banal, o mais significativo dos lugares. Todos os capitais, todos os trabalhos, todas as técnicas e formas de organização podem aí se instalar, conviver, prosperar. Nos tempos de hoje, a cidade grande é o espaço onde os fracos podem subsistir (SANTOS, 1997:258).

Antigamente, dizia-se que a metrópole era o lugar que facilitava mais a penetração do capital estrangeiro, que mais facilitava a entrada dos vetores da modernidade. Essa era a base da teoria dos polos de crescimento e do centro e da periferia (SANTOS, 2003). Entretanto, as redes de difusão dos vetores da modernidade encontram, no campo, um espaço de maior penetração. No campo não há grande concentração de sobreposição de tempos e de formas, ao contrário das grandes cidades, nas quais as formas dificultam a implementação do novo. A cidade torna-se palco das atividades de todos os capitais e de todas as pessoas, inclusive daquelas expulsas do campo pela tecnificação do trabalho agrícola. A presença dessa população, em geral pobre, enriquece a diversidade da produção material em vilas, bairros e favelas, fortalecendo as práticas de vizinhança, de solidariedade e de comunicabilidade. $\mathrm{Na}$ cidade se encontra um caminho possível para um futuro melhor.

$\mathrm{Na}$ verdade, a cidade é um sistema que agrupa tanto uma economia globalizada, seu circuito superior, quanto uma economia popular, seu circuito inferior, produzida a partir das necessidades do lugar (SANTOS, 1979). As cidades apresentam uma sobreposição de diversos sistemas de cooperação e solidariedade.

Não se pode pensar nas cidades somente como espaços passivos das necessidades globais. Elas dependem das relações diretas entre grupos e 
pessoas. A cidade, no sentido de produção local de práticas solidárias, compartilhadas, é obra associada à criação mais do que um simples produto. Se há produção e reprodução das relações sociais na cidade, é porque existe relação entre seres humanos, mais do que produção de objetos. A cidade é obra de uma história e, também, produção dela (LEFEBVRE, 1991b).

Para Milton Santos (1997), as relações de proximidade nas cidades florescem e garantem a comunicação entre as pessoas. Os guetos, as vilas e as favelas tendem a expressar um caráter maior de proximidade, manifestando um conteúdo maior de solidariedade, de comunicação e de copresença, pois de lá se tem a percepção mais clara dos processos que envolvem a cidade. Nesses lugares, os vetores da modernidade chegam depois, as redes de difusão de informação espraiam-se, difundem-se com menor intensidade do que nas regiões economicamente mais ricas da cidade. Isso favorece a percepção de afinidade cultural e econômica das pessoas, propiciando, então, uma prática social e solidária no lugar, na cidade. Nas cidades, como realça Milton Santos, prevalecem os tempos dos homens lentos.
A força é dos lentos e não dos que detêm a velocidade elogiada por um Virilio em delírio, na esteira de um Valéry sonhador. Quem, na cidade, tem mobilidade - e pode percorrê-la e esquadrinhá-la - acaba por ver pouco, da cidade e do mundo. Sua comunhão com as imagens, frequentemente prefabricadas, é a sua perdição. (...) Os homens lentos, para quem tais imagens são miragens, não podem, por muito tempo, estar em fase com esse imaginário perverso e acabam descobrindo as fabulações (SANTOS, 1997:260-261).

Os lentos abrem novas perspectivas para o entendimento dos usos da e na cidade. Às vezes silenciosamente, outras vezes causando barulho. O fato é que eles encontram novas finalidades, novas articulações e normas para a vida social e afetiva.

Trata-se, para eles, da busca do futuro sonhado como carência
a satisfazer - carência de todos os tipos de consumo, consumo
material e imaterial, também carência do consumo político,
carência de participação e de cidadania. Esse futuro é
imaginado ou entrevisto na abundância do outro e entrevisto,
como contrapartida, nas possibilidades apresentadas pelo
Mundo e percebidas no lugar (SANTOS, 1997:261). 
Martins (2000) utiliza os termos homem comum ou homem simples, em vez de pobres ou homens lentos como sugere Milton Santos. Para ele, o homem comum, do tempo e do espaço de todos os dias, é aquele capaz de se organizar, de reivindicar e de solidarizar. Na vida cotidiana, o homem comum descobre sua história e sua importância política, e também sua solidão e suas angústias. O senso comum torna-se instrumento não apenas das repetições e das alienações, mas da copresença, da transformação e da união.

Para Martins (2000), o senso comum tem demonstrado que a privação dos bens materiais e imateriais tem gerado novos significados, novas relações sociais, ou seja, ameaças de rupturas do sistema. Os significados são reinventados continuamente e as desordens sociais são resolvidas pelo homem comum, porque ele dispõe de seu próprio meio para refletir e agir perante as dificuldades. Ademais, os homens que vivem e compartilham os mesmos trajetos, as mesmas histórias, as mesmas imagens fabricam sua própria vida no lugar. $\mathrm{O}$ mundo da globalização, porém, tende a modificar essa realidade, tornando mais veloz o movimento das inovações, das normas e das divisões do trabalho. A circulação se sobrepõe à produção, assim como a velocidade se sobrepõe ao repouso. A circulação de pessoas e de mercadorias aumenta vertiginosamente, provocando uma sensação de desterritorialidade que atinge uma parcela da sociedade, especialmente os migrantes.

A migração para as cidades significa deixar para trás todo um modo de vida, toda uma cultura. Assim, o imigrante, ao encontrar outro lugar que não ajudou a construir, pode sentir certo estranhamento perante o espaço cuja história e memória ele desconhece.

Por outro lado, mesmo sem condições adequadas de higiene, sem infraestrutura urbana, sem emprego, esse sujeito enfrenta as adversidades e vive. A memória e a prática do passado passam a não significar muito na realidade do presente. A memória do passado cede lugar a uma nova forma de interpretar a cidade e o cotidiano. O novo território e a nova cultura com que depara o imigrante o transformam, o integram com os demais moradores, o fazem perceber a necessidade de se solidarizar, de compartilhar sua angústia e sua esperança. Dessa forma, a alienação do

\footnotetext{
${ }^{9}$ Martins assim define senso comum: "O senso comum é comum não porque seja banal ou mero e exterior conhecimento. Mas porque é conhecimento compartilhado entre sujeitos da relação social. Nela o significado a precede, pois é condição de seu estabelecimento e ocorrência. Sem significado compartilhado não há interação. Além disso, não há possibilidade de que os participantes da interação se imponham significados, já que o significado é reciprocamente experimentado pelos sujeitos" (MARTINS, 2000:59).
} 
primeiro momento cede espaço à integração e à cooperação. "A consciência pelo lugar se sobrepõe à consciência no lugar. A noção de espaço desconhecido perde a conotação negativa e ganha um acento positivo, que vem do seu papel na produção de uma nova história" (SANTOS, 1997:264).

Ao contrário do que diz o pensamento hegemônico, quanto menos inserido for o homem na sociedade e no lugar, maior será a probabilidade de encarar as novidades e de descobrir novas formas de viver (SANTOS, 1997).

\section{Considerações finais}

O lugar, espaço de convergência de vários vetores da modernidade, é produzido por uma lógica externa do capital à busca de maior lucratividade. Mas é, também, produtor de uma dinâmica interna de solidariedade. Tal dinâmica decorre das características locais e de suas próprias necessidades de produção e reprodução social.

Essa confluência do interno com o externo, de uma ação solidária com a organizacional, produz a conexão do conceito de região na geografia lablacheana com o conceito de região funcional de Bernard Kaiser. Resguardadas as particularidades históricas dessas concepções, a homogeneidade e a coesão da região geográfica de La Blache são substituídas, por Milton Santos, pela heterogeneidade própria do período técnico-científico-informacional. Ele resgata, pelo conceito de lugar, a importância de compreender tanto a dinâmica interna quanto sua funcionalidade externa, conforme o conceito de Kaiser.

É o retorno à dialética da totalidade que se expande e se fragmenta, que incorpora não somente a produção em seu sentido restrito, mas também as criações humanas calcadas na realidade de cada lugar e do mundo. A totalidade é sempre um movimento que se expande e se contrai num eterno devir. A região e o espaço são pares dialéticos do movimento da totalidade. A região e o lugar somente fazem sentido no contexto da totalidade, mas o espaço somente faz sentido em suas particularidades. Esse enfoque centrado na categoria de totalidade não diminui, nem desvaloriza, o conceito de região, segundo Milton Santos - apenas faz transparecer a dialética entre esses conceitos, que são realidades inseparáveis, pois um depende do outro para sua explicação e para a realização de práticas sociais. 
Região e lugar se identificam, contudo, na realidade da cidade, o espaço da ordem precisa, da ação condicionada, assim como da contiguidade, da coabitação, da vizinhança, da proximidade e da comunicação. Nas cidades há difusão de vários vetores da modernidade, tanto os representados pela lógica hegemônica do capital quanto os que a ela se opõem. A cidade é, portanto, o grande lugar que possibilita diferentes interpretações e ações no mundo.

A cidade representa, para Milton Santos, não só a arena possível para a construção de estratégias para a transformação, como o espaço amplo para a mudança na vida das classes e grupos subordinados. A cidade é o espaço possível para a política, para a redefinição de propostas ambiciosas e realistas, caminho para a transformação urbana permanente.

O otimismo de Milton Santos - tendo a cidade como ponto de partida para as transformações sociais, e a população carente e pobre como o principal agente dessas transformações - pode, porém, não encontrar tanto respaldo na realidade socioespacial das metrópoles contemporâneas. As perspectivas de mudança ainda estão obscuras, bem como o próprio processo da globalização. Até que ponto os movimentos de resistência assumem uma visão emancipatória que conteste o mundo das mercadorias? A resposta a essa questão ainda não está tão nítida, mesmo que melhorias substantivas no espaço urbano tenham sido conquistadas por alguns movimentos sociais.

Sintetizando, a partir do conceito de lugar e de cidade, Milton Santos recupera a dialética do universal e do particular. $\mathrm{O}$ autor não apenas percebe a importância de compreender a desigualdade socioespacial gerada pelo modo de produção capitalista global, mas percebe a diversidade regional, como consequência de uma produção, no sentido amplo lefebvriano, de desejos, de angústias, de esperanças que nascem conforme o cotidiano dos lugares e do mundo. O conceito de totalidade, como o movimento do universal e do particular, permite, ao autor, redescobrir a importância dos recortes espaciais para compreender o homem e seu espaço como pares complementares e indispensáveis da dialética socioespacial.

\section{A METAMORFOSE DO CONCEITO DE REGIÃO: LEITURAS DE MILTON SANTOS}

Resumo: A região em Milton Santos é concebida, em princípio, como funcional em relação ao modo de produção global, que dá sentido à sua realidade interna. Isso não significa que cada região não tenha suas particularidades. Pelo contrário, no desenvolvimento de sua obra, Milton Santos chega ao conceito de lugar, que abrange tanto um espaço de 
determinações externas quanto um espaço de solidariedade, de vivências internas. Região e lugar se identificam na cidade, onde há o encontro e o desencontro de múltiplos vetores da modernidade, no teatro das ações humanas. Desse modo, na cidade, Milton Santos se encontra com a dialética do global e do local, com a totalidade das relações socioespaciais construída no movimento que não omite a relevância das particularidades do lugar ou da região.

Palavras-chave: Milton Santos; região; lugar; cidade; espaço; totalidade.

\section{METAMORPHOSIS OF THE REGION CONCEPT: MILTON SANTOS READINGS}

Abstract: The region for Milton Santos is conceived, in principle, as functional to the global production mode, which imprints sense to its internal reality. This does not mean that each region does not have its particularities. Quite the opposite, in the development of its work, Milton Santos arrives at the concept of place, that includes a space of external determination and a solidarity space, of internal experiences. Region and place embodies themselves in the city, where multiple vectors of modernity encounter and miss each other in the realm of the human action. Therefore in the city Milton Santos deals with the dialectic of the global and the place, with the totality of the social-spatial relations built as movement that does not loose the relevance of the specificities of place and region.

Keywords: Milton Santos; region; place; city; space; totality.

\section{Bibliografia}

BALBIM, R. N. (2001). Região, território, espaço: funcionalizações e interfaces. In: CARLOS, A. F. A. (Org.). Ensaios de geografia contemporânea. São Paulo: Hucitec, p. 160-169.

CASTRO, I. E. (2002). A região como problema para Milton Santos. Scripta Nova, Universidad de Barcelona, v. VI, n. 124 ("El ciudadano, la globalización y la geografía. Homenaje a Milton Santos"), p. 1-6, 30 set.

CORRÊA, R. L. (1997). Trajetórias geográficas. Rio de Janeiro: Bertrand Brasil.

CUNHA, A. M.; SIMÕES, R. F.; PAULA, J. A. de (2005). Regionalização e história: uma contribuição introdutória ao debate teórico-metodológico. Textos para Discussão, Belo Horizonte, Cedeplar-UFMG, n. 260, maio.

FRÉMONT, A. (1980). A região, espaço vivido. Coimbra: Almedina. 
GOMES, P. C. da C. (1995). O conceito de região e sua discussão. In: CASTRO, I. E. de et al. (Org.). Geografia: conceitos e temas. Rio de Janeiro: Bertrand Brasil, p. 49-76.

HAESBAERT, R. (1999a). Região, diversidade territorial e globalização. Geographia: revista da Pós-Graduação em Geografia da UFF, Niterói, ano I, n. 1, p. 15-39.

(1999b). Identidades territoriais. In: ROSENDAHL, Z.; CORREAA, R. L. (Org.). Manifestações da cultura no espaço. Rio de Janeiro: Uerj, p. 169-190. (Col. Geografia Cultural).

HALL, S. (2004). A identidade cultural na pós-modernidade. Rio de Janeiro: DP\&A.

HELLER, A. (s.d.). O cotidiano e a história. 4. ed. São Paulo: Paz e Terra. KAISER, B. (1973). A região como objeto de estudo da geografia. In: GEORGE, P. et al. (Org.). A geografia ativa. 3. ed. São Paulo: Difusão Europeia do Livro, p. 279-321.

LEFEBVRE, H. (1991a). A vida cotidiana no mundo moderno. São Paulo: Ática.

(1991b). O direito à cidade. São Paulo: Moraes.

LENCIONI, S. (1999). Região e geografia. São Paulo: Edusp.

MARTINS, J. de S. (2000). A sociabilidade do homem simples. São Paulo: Hucitec.

SANTOS, M. (1978). O trabalho do geógrafo no Terceiro Mundo. São Paulo: Hucitec.

(1979). O espaço dividido: os dois circuitos da economia urbana dos países subdesenvolvidos. 2. ed. Rio de Janeiro: Livraria Francisco Alves Editora.

(1985). Espaço e método. São Paulo: Nobel.

(1988). Metamorfoses do espaço habitado. São Paulo: Hucitec.

(1991). A revolução tecnológica e o território: realidades e perspectivas. Terra Livre- $A G B$, São Paulo, n. 9, p. 7-18, jul./dez.

(1994a). Técnica, espaço, tempo: globalização e meio técnico-

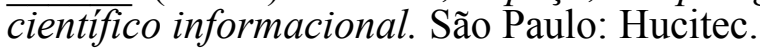

(1994b). O retorno do território. In: SANTOS, M. et al. (Org.). Território: globalização e fragmentação. São Paulo: Hucitec/Anpur, p. 1520.

(1996). Por uma geografia cidadã: por uma epistemologia da existência. Boletim Gaúcho de Geografia, Porto Alegre, n. 21, p. 7-14. 
(1997). A natureza do espaço: técnica e tempo, razão e emoção. 2. ed. São Paulo: Hucitec.

(1999). Modo de produção técnico-científico e diferenciação espacial. Revista Território, Rio de Janeiro, ano IV, n. 6, p. 5-20, jan./jun. (2000a). Por uma outra globalização: do pensamento único à consciência universal. Rio de Janeiro: Record.

(2000b). Território e sociedade: uma entrevista com Milton Santos. São Paulo: Fundação Perseu Abramo. (2002). Testamento intelectual. São Paulo: Ed. Unesp.

(2003). Região: globalização e identidade. In: LIMA, L. C. (Org.). Conhecimento e reconhecimento: uma homenagem ao geógrafo cidadão do mundo. Fortaleza: Eduece/LCR, p. 53-64.

SORRE, M. (1967). El hombre en la tierra. Barcelona: Editorial Labor. 